\title{
Numerical Simulation of Residual Behavior of Steel Concrete Interface after High Temperature Exposure
}

\author{
Ziyad Zenasni ${ }^{1{ }^{1 *}, \text { Mohamed Haterbouch }}{ }^{1}$, Khalid Nasri ${ }^{2}$, Mohammed Zenasni ${ }^{3}$, Rajae Addou ${ }^{3}$, \\ Kinda Hannawid ${ }^{4}$, William Prince Agbodjand ${ }^{4}$

\begin{abstract}
${ }^{1}$ Department of Mechanics and Integrated Engineering (M2I), National School of Arts and Crafts Meknes, Moulay Ismaïl University, B.P. 15290 Al-Mansor, Meknes, Morocco

${ }^{2}$ Department of Industrial and Civil Sciences and Technologies (STIC), National School of Applied Sciences, Tetouan, Morocco ${ }^{3}$ Department of Mechanics and Scientific Computing, BP 669, National School of Applied Sciences, 60000 Oujda, Morocco

${ }^{4}$ Laboratory of Civil and Mechanical Engineering, 20 Avenue des Buttes de Coësmes, CS 70839, 35708 Rennes Cedex 7, France
\end{abstract}

Received January 31, 2021; Revised March 23, 2021; Accepted April 18, 2021

\section{Cite This Paper in the following Citation Styles}

(a): [1] Ziyad Zenasni, Mohamed Haterbouch, Khalid Nasri, Mohammed Zenasni, Rajae Addou, Kinda Hannawid, William Prince Agbodjand, "Numerical Simulation of Residual Behavior of Steel Concrete Interface after High Temperature Exposure," Civil Engineering and Architecture, Vol. 9, No. 3, pp. 625-633, 2021. DOI: 10.13189/cea.2021.090306.

(b): Ziyad Zenasni, Mohamed Haterbouch, Khalid Nasri, Mohammed Zenasni, Rajae Addou, Kinda Hannawid, William Prince Agbodjand (2021). Numerical Simulation of Residual Behavior of Steel Concrete Interface after High Temperature Exposure. Civil Engineering and Architecture, 9(3), 625-633. DOI: 10.13189/cea.2021.090306.

Copyright $\bigcirc 2021$ by authors, all rights reserved. Authors agree that this article remains permanently open access under the terms of the Creative Commons Attribution License 4.0 International License

\begin{abstract}
Behaviour of reinforced concrete and prestressed concrete structures subjected to fire is an important research theme in civil engineering. In addition, experiment investigations show that the concrete behavior is strongly affected by temperature. The aim of this work is to study numerically the residual behavior of steel-concrete bond after high temperature exposure. To do a numerical study, bond stress at the steel-concrete interface were developed using a concrete damage plasticity model (CDP model) implemented in the nonlinear finite element software «ABAQUS». The physical, mechanical and damage plasticity parameters (compressive damage and tensile damage) required for the model were drawn from previous literature works and the model was validated by simulating the uniaxial compression strength test under different temperatures using Abaqus code. The model was finally applied to simulate a pull-out test made on a reinforced concrete specimen heated at various temperature $\left(105^{\circ} \mathrm{C}, 150^{\circ} \mathrm{C}, 200^{\circ} \mathrm{C}, 300^{\circ} \mathrm{C}, 400^{\circ} \mathrm{C}\right.$ and $500^{\circ} \mathrm{C}$.) and then cooled at room temperature. The numerical results show a good correlation with the experimental results and clearly indicate a deterioration of bond performance when temperature increased, particularly the bond stress, bond stiffness and pull-out force. The model was also used to validate the results of
\end{abstract}

initiation and propagation of cracks.

Keywords Pull Out Test, Steel-Concrete Interface, CDP Model, High Temperature, Abaqus

\section{Introduction}

Concrete is a heterogeneous material at different level of observation: from the nanometer (scale of the basic components of the cement paste) to the centimeter (representative scale of coarse aggregates). In several domains of civil engineering, this material is increasingly used (building, tunnel, oil platforms, nuclear power plants, storage sites, ...), which can sometimes be exposed to severe conditions, fire, flood, earthquake etc. For this, many experimental study and models are developed considering the effect of different physicochemical, microstructural, and geometrical parameters on the mechanical behavior of structures and influencing the stability of concrete [1-8].

The stability depends on the cohesion at the interface between the concrete and the steel reinforcement, which can be evaluated by measuring the maximum value of 
pulling force and by studying behavior of the composite during the pull-out test. In fact, several experimental and numerical studies have been carried out over the last decade to assess the adhesion between steel and concrete under severe conditions of mechanical and thermal loading, for example the work of [9-15]. These studies have revealed that concrete presents a good performance regarding its fire resistance thanks to all the physicochemical characteristics that concrete presents, such as its strength especially to compression, its low thermal diffusion etc. On the other hand, the mechanical properties of concrete are much influenced by a long exposure to high temperatures, especially between $400^{\circ} \mathrm{C}$ and $500^{\circ} \mathrm{C}$. For a good modeling of the mechanical behavior of reinforced concrete structures exposed to fire, it is necessary to take into account all the parameters related to temperature, because the latter has a huge influence on the stability of the reinforced concrete structure and mainly on the adhesion at the interface between steel and concrete.

The main task of this works is to investigate the residual behavior of steel concrete interface after high temperature exposure. To do this, what we do first is to exploit some experimental results given in the literature, $[16,17]$ concerning the residual compressive strength of a concrete exposed to high temperature. From these results, the evolutive values of the different concrete parameters (particularly the Young's modulus) when the temperatures varied has been extracted and used to validate the numerical model. Secondly, the experimental and numerical results [17-19] of the stress-strain curves and the damage evolution were used to finalize our numerical program and simulate the pull-out tests.

\section{Materials and Methods}

\subsection{Identification of the Constitutive Parameters Required by the CDP Model}

The main task in failure description is the recognition of crack patterns. Concrete Damage Plasticity (CDP), introduced by Kachanov and further developed by Rabotnov [20] and others [21-25], is one of the possible constitutive models. The constitutive equation of material with scalar isotropic damage takes the following form equation (1) and equation (2):

$$
\begin{gathered}
\sigma_{t}=\sigma_{t}\left(\tilde{\varepsilon}_{t}^{p l}, \dot{\tilde{\varepsilon}}_{t}^{p l}, T, f_{i}\right) \\
\sigma_{c}=\sigma_{c}\left(\tilde{\varepsilon}_{c}^{p l}, \dot{\tilde{\varepsilon}}_{c}^{p l}, T, f_{i}\right)
\end{gathered}
$$

Where the subscripts $\mathrm{t}$ and $\mathrm{c}$ refer to tension and compression, respectively; $\tilde{\varepsilon}_{\mathrm{c}}^{\mathrm{pl}}$ and $\tilde{\varepsilon}_{\mathrm{t}}^{\mathrm{pl}}$ are the equivalent plastic strains, $\dot{\tilde{\varepsilon}}_{\mathrm{c}}^{\mathrm{pl}}$ and $\dot{\tilde{\varepsilon}}_{\mathrm{t}}^{\mathrm{pl}}$ are the equivalent plastic strain rates, $\mathrm{T}$ is the temperature, and $\mathrm{fi}(\mathrm{i}=$ $1,2,3, \ldots$.$) are other predefined field variables.$
As shown in Figure. 1, when the concrete specimen is unloaded from any point on the strain softening branch of the stress-strain curves, the unloading response is weakened: the elastic stiffness of the material appears to be damaged (or degraded). The degradation of the elastic stiffness is characterized by two damage variables, $d t$ and dc, which are assumed to be functions of the plastic strains, temperature, and field variables as presented in equation (3) and equation (4):
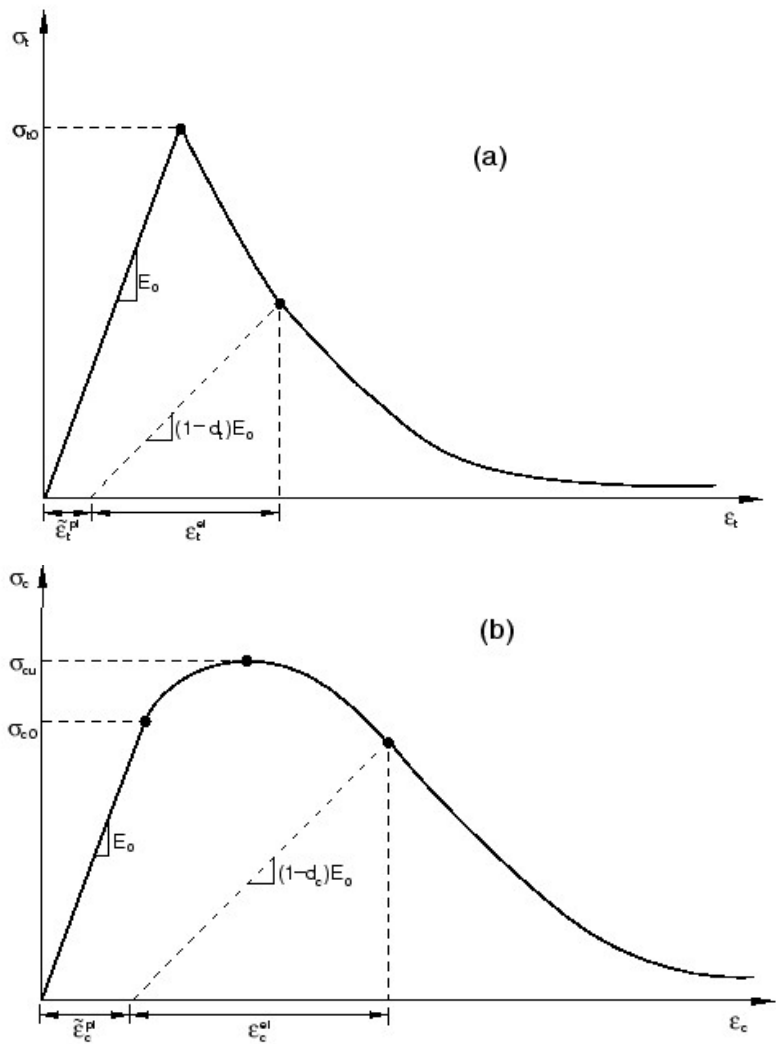

Figure 1. Response of concrete to uniaxial loading in tension (a) and compression (b)

$$
\begin{array}{ll}
d_{t}=d_{t}\left(\tilde{\varepsilon}_{t}^{p l}, T, f_{i}\right) ; & 0 \leq d_{t} \leq 1 \\
d_{c}=d_{c}\left(\tilde{\varepsilon}_{c}^{p l}, T, f_{i}\right) ; & 0 \leq d_{c} \leq 1
\end{array}
$$

The damage variables can take values from zero, representing the undamaged material, to one, which represents total loss of strength.

If $E_{0}$ is the initial (undamaged) elastic stiffness of the material, the stress-strain relations under uniaxial tension (equation (5)) and compression loading (equation (6)) are, respectively:

$$
\begin{gathered}
\sigma_{t}=\left(1-d_{t}\right) E_{0}\left(\varepsilon_{t}-\tilde{\varepsilon}_{t}^{p l}\right) \\
\sigma_{c}=\left(1-d_{c}\right) E_{0}\left(\varepsilon_{c}-\tilde{\varepsilon}_{c}^{p l}\right)
\end{gathered}
$$

The "effective" tensile and compressive cohesion stresses are respectively expressed by equation (7) and equation (8):

$$
\bar{\sigma}_{t}=\frac{\sigma_{t}}{\left(1-d_{t}\right)}=E_{0}\left(\varepsilon_{t}-\tilde{\varepsilon}_{t}^{p l}\right)
$$




$$
\bar{\sigma}_{c}=\frac{\sigma_{c}}{\left(1-d_{c}\right)}=E_{0}\left(\varepsilon_{c}-\tilde{\varepsilon}_{c}^{p l}\right)
$$

The effective cohesion stresses determine the size of the yield (or failure) surface. The effective stress is defined by equation (9):

$$
\bar{\sigma}=D_{0}^{e l}:\left(\varepsilon-\varepsilon^{p l}\right)
$$

The concrete damaged plasticity model assumes nonassociated potential plastic flow. The model makes use of the yield function of Lubliner et. al. [26], with the modifications proposed by Ghosh et al. [27] to account for different evolution of strength under tension and compression.

\subsection{Experimental Test and Model Validation}

The concrete damage plasticity model in Abaqus [28] is used in this study, assuming that in both case of compression and tensile behavior, the concrete is affected by plastic damage. To validate this numerical model, this study proposes a numerical simulation of the uniaxial compressive test on a concrete specimen.

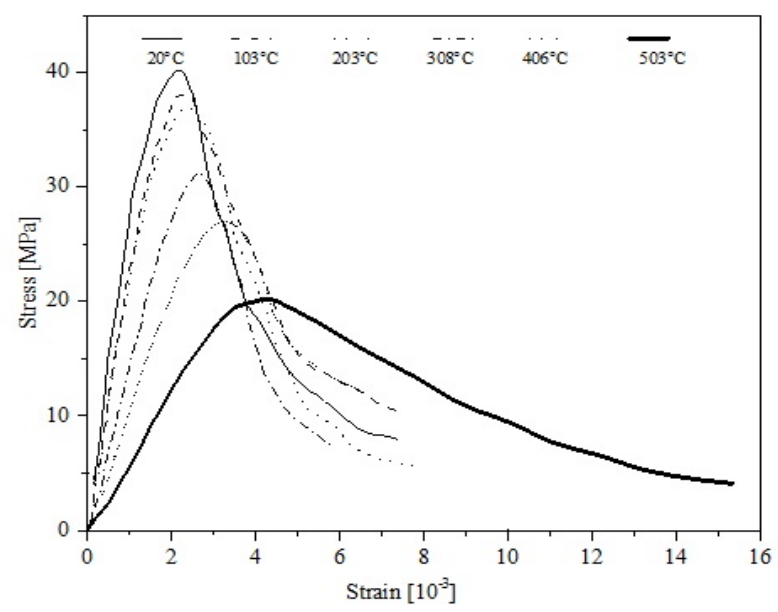

Figure 2. Experimental stress-strain curves after heating for different temperatures, [16].

This simulation is based on the experimental work of Chang et al. [16]. The authors of this work [16] give several experimental results but this paper is mainly interested in the results concerning the evolution for different temperatures of the compressive stresses-strain curves as shown in Figure. 2.

From these curves, it can be noticed that when the temperature increases, the young modulus decreases, the peak-strength decreases, and the post-peak curve tends to be flatter. This means that the concrete tends to be more ductile.

\subsubsection{Physical and mechanical properties required by the model}

To calibrate this model, the designation and properties of concrete used in this study are listed in Table 1.
Table 1. Properties of concrete used in the validation study [29, 30]

\begin{tabular}{|c|c|c|c|}
\hline Density & \multicolumn{3}{|c|}{$2.410-9 \mathrm{~T} / \mathrm{mm} 3$} \\
\hline $\mathrm{T}\left({ }^{\circ} \mathrm{C}\right)$ & $\mathrm{E}(\mathrm{MPa})$ & $\mathrm{k}(\mathrm{J} . \mathrm{s}-1 . \mathrm{m}-1 . \mathrm{K}-1)$ & $\mathrm{C}(\mathrm{N} . \mathrm{m} . \mathrm{s}-1 . \mathrm{K}-1)$ \\
\hline 20 & 35000.00 & 2 & 901104000 \\
\hline 105 & 30091.25 & 1.79 & 945261500 \\
\hline 150 & 27492.50 & 1.698 & 966650000 \\
\hline 200 & 24605.00 & 1.204 & 988800000 \\
\hline 300 & 18830.00 & 1.1274 & 1028000000 \\
\hline 400 & 13055.00 & 1.05 & 1060400000 \\
\hline 500 & 7280.00 & 0.988 & 1086000000 \\
\hline
\end{tabular}

Where $\mathrm{T}$ is temperature, $\mathrm{E}$ is Young's modulus, $\mathrm{C}$ (N.m.s-1. K-1) is specific heat, and k (J.s-1.m-1. K-1) is thermal conductivity.

\subsubsection{Simulation of uniaxial compression test}

The objective of this part is the presentation of the numerical simulation of the uniaxial compression test. Figure. 3 shows the numerical model created on Abaqus, [28] and applied for concrete heated at different temperatures. The stress strain curves obtained numerically after heating for different temperatures $\left(\mathrm{T}=200^{\circ} \mathrm{C}, 300^{\circ} \mathrm{C}\right.$, $400^{\circ} \mathrm{C}$ and $500^{\circ} \mathrm{C}$ ), have the same behavior as those given by Chang et al. [16].

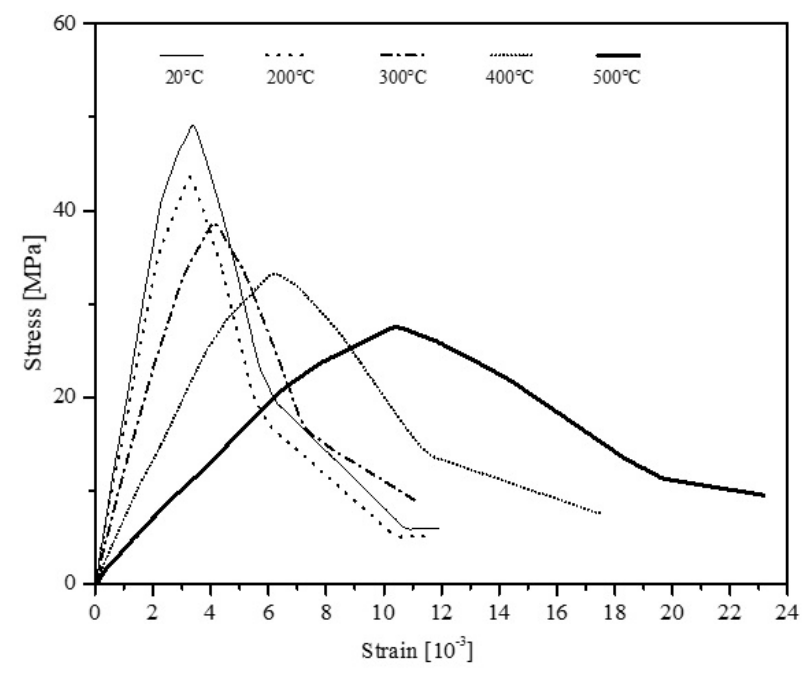

Figure 3. Numerical stress-strain curves after heating for different temperatures.

Thus, this study clearly notices the numerical effect of the residual stress strain relationship of concrete. However, the difference of stress-strain values between this work and Chang et al. [16] results has been observed. This is due to the difference of concrete class used in each test. As mentioned previously, the pull-out test given in section 4 and section 5 referred to a concrete that have $50 \mathrm{MPa}$ compressive strength while the concrete used by Chang et al. [16] and mentioned in this section, have only $40 \mathrm{MPa}$ compressive strength, which is a less performing concrete. So, it appears at this stage of this work that the 
numerical model including concrete damage plasticity model gives a very efficient reporting of the residual stress-strain curves obtained on concrete previously exposed to high temperatures.

\subsection{Investigations on Concrete Pull-Out Test Based on Finite Element Modeling}

To numerically model this test, the C.P.E.4.R ("4-Node bilinear Plane Strain Quadrilateral Reduced Integration) elements were selected for concrete. After meshing, the number of elements in model is 26018,26806 nodes and 80419 variables. The interface modeling on Abaqus uses a master-slave contact. The principle of this code considers that the nodes of the slave surface cannot penetrate the segments that form the master surface. This code was implemented in Abaqus, [28] by the keyword "contact pair, interaction $=$ intprop- 1 , mechanical constraint $=$ kinematic, small sliding, cpset $=$ int-1 m_surf, s_surf".
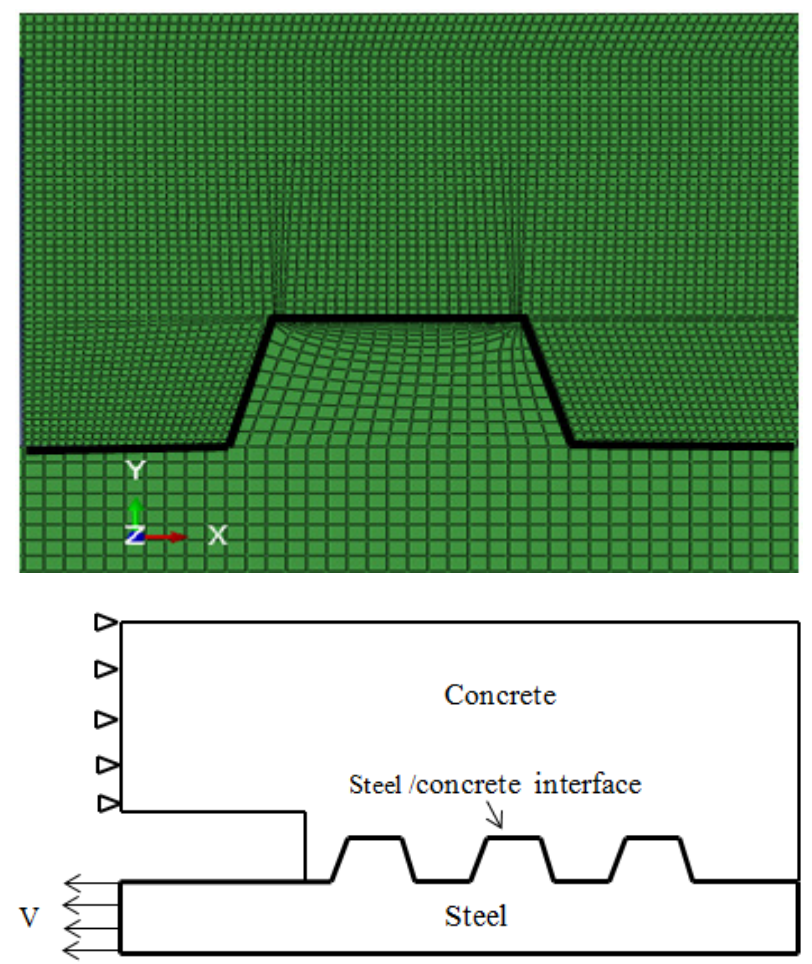

Figure 4. Finite elements mesh near the interface steel concrete.

The thermal properties can be included in a contact property definition by modeling conductance between surfaces. The conductive heat transfer between the contact surfaces is assumed to be defined by equation (10):

$$
q=k\left(T_{A}-T_{B}\right)
$$

Where, : is the heat flux per unit area crossing the interface from point $A$ on one surface to point $B$ on the other, $\mathrm{T}_{\mathrm{A}}$ and $\mathrm{T}_{\mathrm{B}}$, are the temperatures of the points on the surfaces and $k:$ is the gap conductance. It can be defined directly or by subroutine gapcon [28].

\section{Results and Discussion}

\subsection{Evolution of the Force-Slip Curves for Different Temperatures of Heating}

The complete pull-out force-displacement curves for different temperatures are shown in Figure 5. The following conclusions can be draw:

1. The effect of high temperatures affects the initial tangent of the curves and therefore the shape of the curves. The residual effect of high temperatures is significant in the initial tangent of the curve only for high temperatures as in the case of $\mathrm{T}=500^{\circ} \mathrm{C}$.

2. With the increase of temperature, the pull-out force decreases, and the slip values decrease also especially for $\mathrm{T}=500^{\circ} \mathrm{C}$.

3. After temperature loading with $20^{\circ} \mathrm{C}, 105^{\circ} \mathrm{C}, 150^{\circ} \mathrm{C}$, $200^{\circ} \mathrm{C}$, and $300^{\circ} \mathrm{C}$, the shape of ascending curves for heated concrete has the same tendencies.

4. The strength reduction after temperature loading with $20^{\circ} \mathrm{C}, 105^{\circ} \mathrm{C}, 150^{\circ} \mathrm{C}, 200^{\circ} \mathrm{C}$, and $300^{\circ} \mathrm{C}$ is not more as $40 \%$. This tendencies change with $400^{\circ} \mathrm{C}$ and $500^{\circ} \mathrm{C}$, where the pulling force decreases (from $\operatorname{fmax}\left(\mathrm{T}=20^{\circ} \mathrm{C}\right)=82 \mathrm{kN}$ to $\operatorname{fmax}\left(\mathrm{T}=500^{\circ} \mathrm{C}\right)=27$ $\mathrm{kN}$ ); this reduction of strength for $\mathrm{T}=500^{\circ} \mathrm{C}$ is about $68 \%$. The displacement value, corresponding to the maximum pulling force, is generally between $\delta=0.8 \mathrm{~mm}$ and $\delta=1 \mathrm{~mm}$, except for two temperatures cases $\left(400^{\circ} \mathrm{C}\right.$ and $\left.500^{\circ} \mathrm{C}\right)$ where this value decreases to $0.57 \mathrm{~mm}$. Besides, as the temperature increases, the descending curves become less flat, the behavior becomes more fragile with increase in temperature.

\subsection{Evolution of the Adhesion Stress-Slip Curves for Different Temperatures of Heating}

Determination of adhesion stress is done directly by the following relation, $\tau_{a}=\left(f / l_{a} \cdot \pi . \varphi\right)$ where $\mathrm{f}$ is pulling force, $\varphi$ is diameter of steel and is $l_{a}$ adhesion length. The adhesion stress-displacement curves for different degrees of temperatures are shown in Figure 6. 


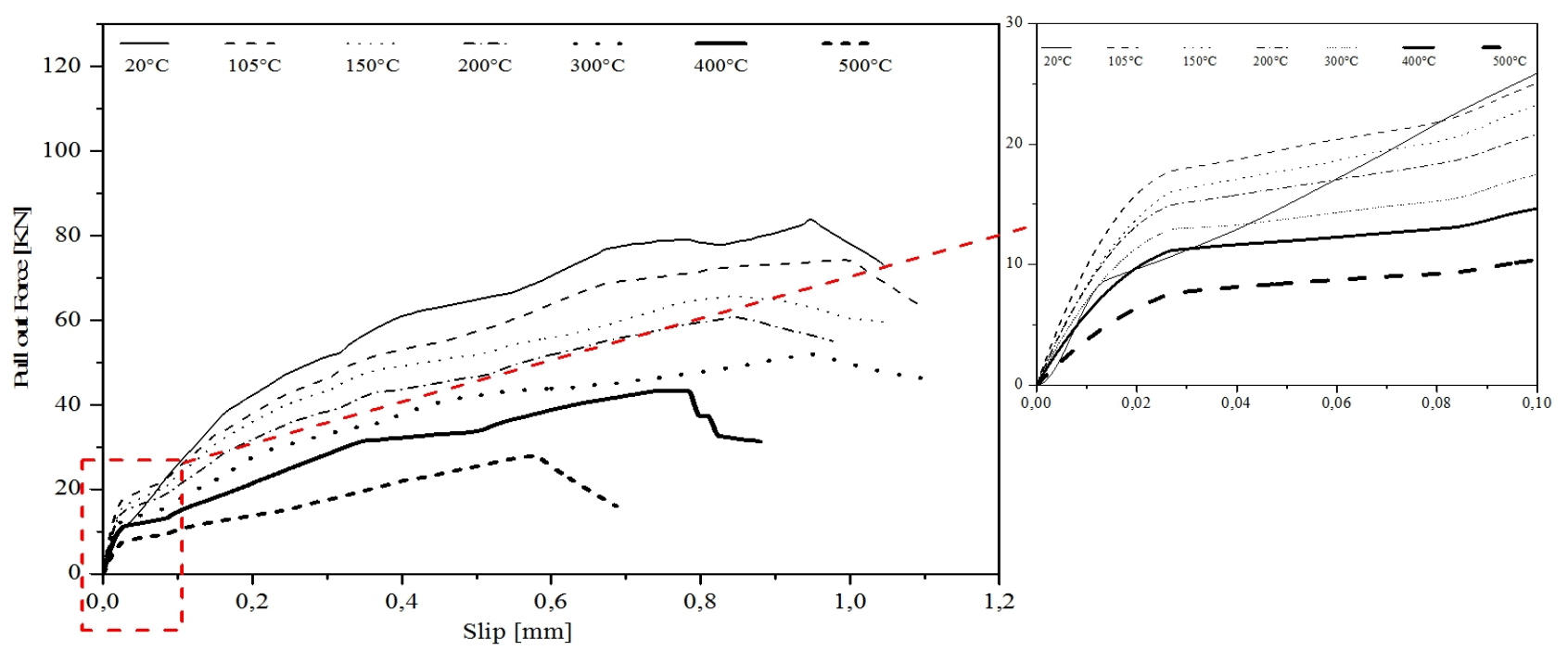

Figure 5. Pull-out force-slip curves for different temperatures.

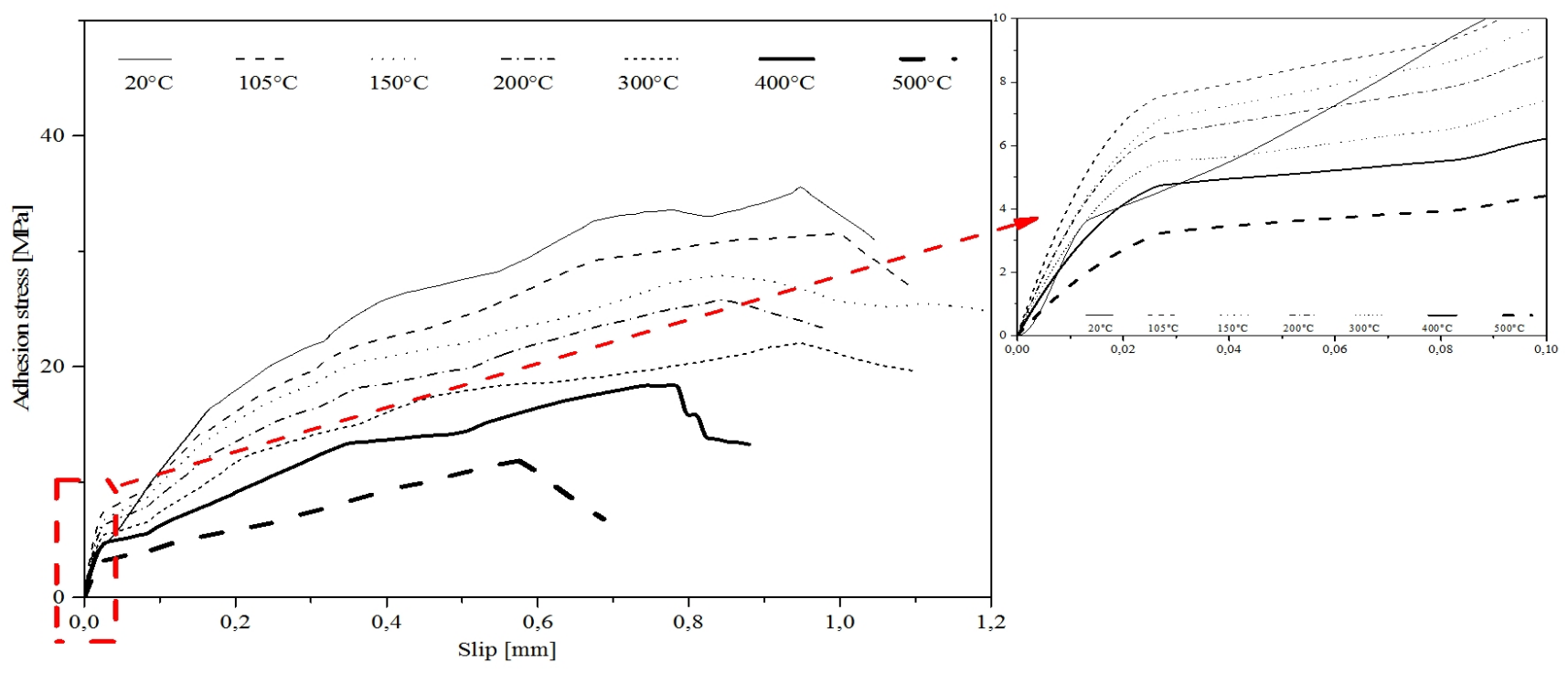

Figure 6. Adhesion stress-slip curves for different temperatures.

The interface resistance between concrete and steel decreases with increasing temperature. The same shape of the adhesion stress curves is illustrated in the Figure 6. Figure 5 represents the evolution of the pulling for different temperatures.

\subsection{Evolution of the Compressive Damage Curves for Different Temperatures of Heating}

The curves shown in Figure 7 describe the evolution of concrete compressive damage curves for different temperatures of heating.

The evolution of compressive damage for an element at the interface rapidly passes from its minimum value $\mathrm{dc}=0$ to its maximum value $\mathrm{dc}=0,89$. Also, the initiation of damage is strongly favored by the effect of high temperatures. The same remarks were noted on the previous Figures. 6-5. It could be suggested that the critical value occurred when the concrete immediately beneath the ribs on the bar reached its maximum compressive strength, resulting in failure permitting increased slip. At the higher temperatures $\left(400\right.$ and $\left.500^{\circ} \mathrm{C}\right)$ no such critical value is seen. This is because the concrete strength was reduced to such an extent that the concrete beneath the ribs failed during the heating-up cycle under a steady-state bond stress, as opposed to during loading to failure after cooling had taken place. 


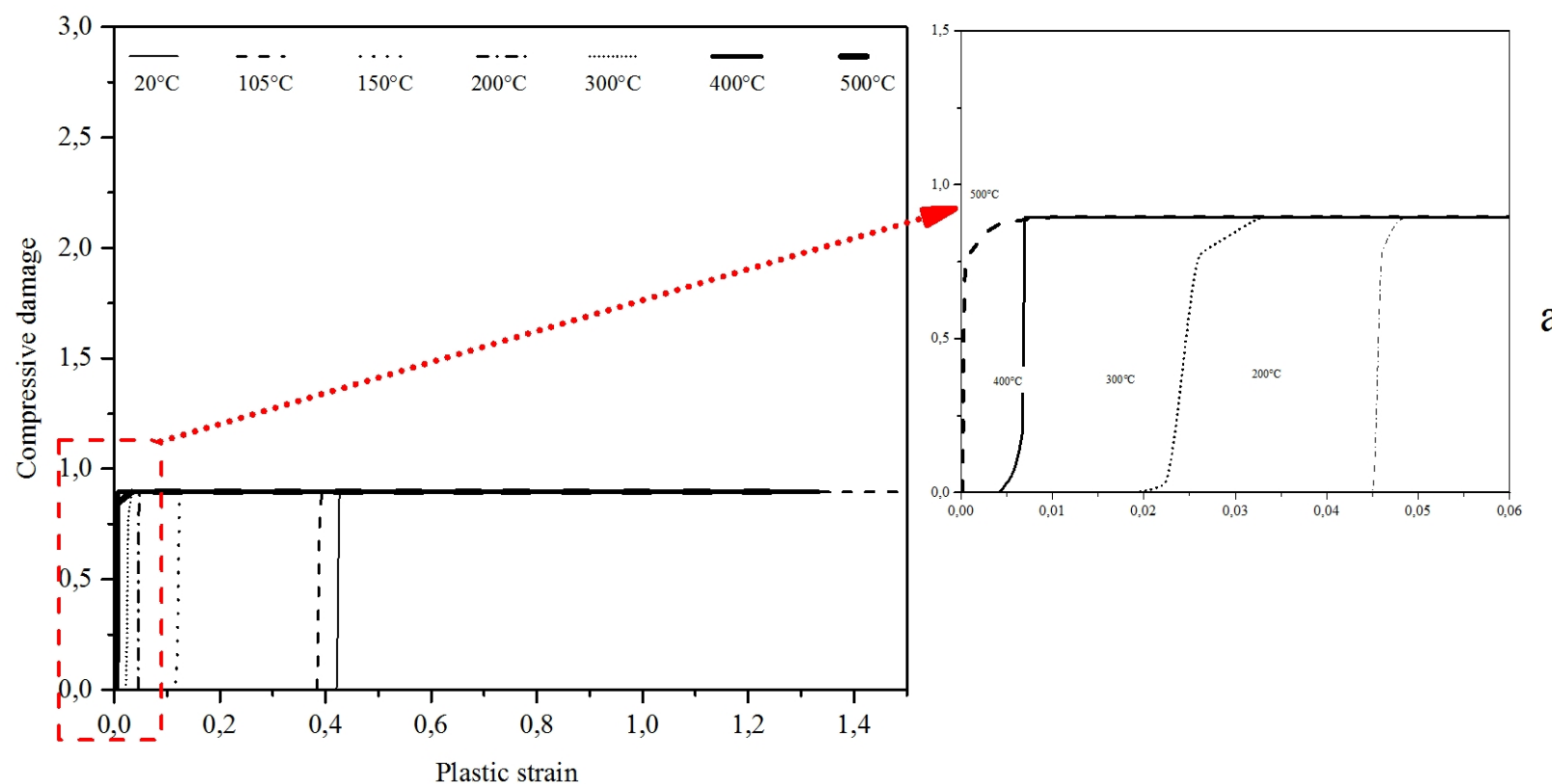

a

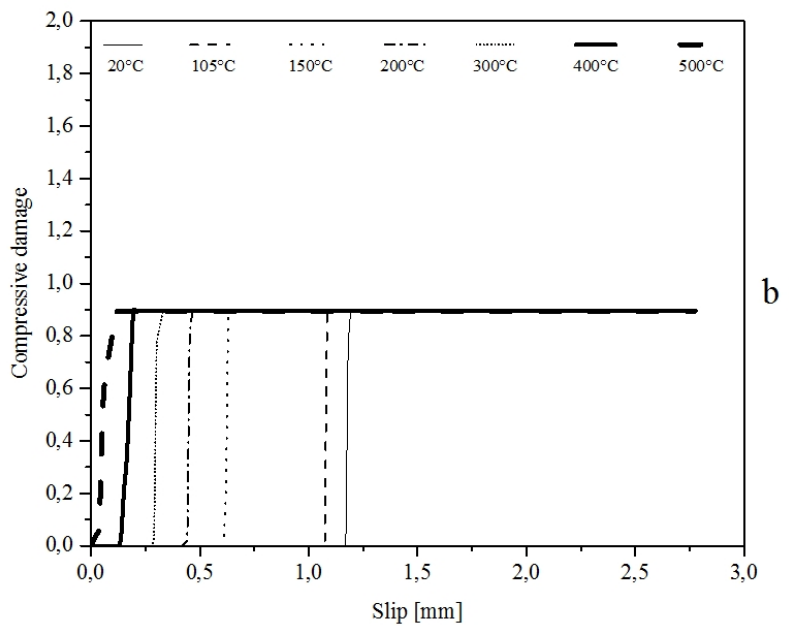

Figure 7. Evolution of concrete compressive damage at different temperatures, (a) compressive damage-plastic strain curves, (b) compressive damage-slip curves. 


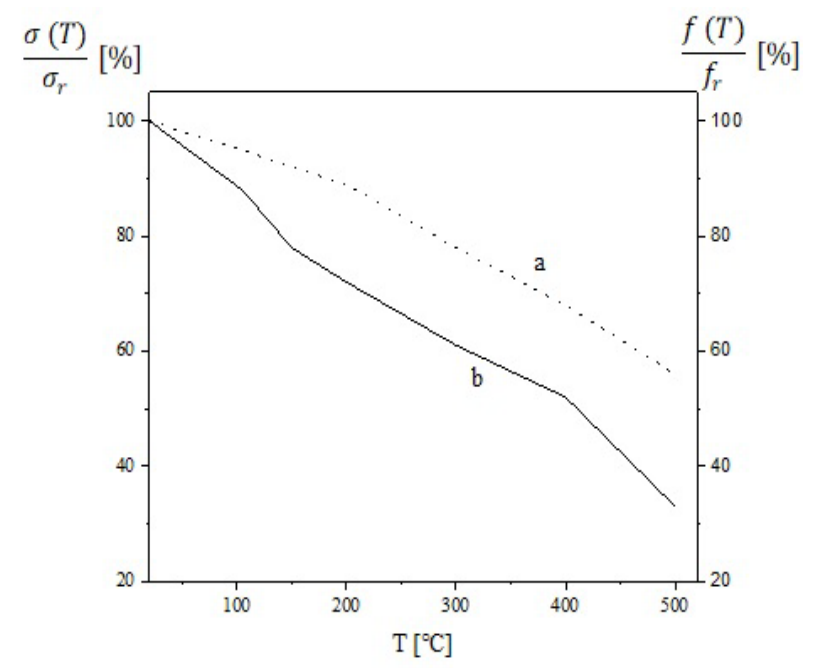

Figure 8. Relationships between maximum bond stress and temperature, (a) relative strength curve of concrete, (b) relative pull-out force.

All these results are supported by the evolution as a function of the temperature of the relative values of resistance and relative pull-out force of concrete, as shown in Figure 8.

\subsection{Evolution of the Tensile Damage Curves for Different Temperatures of Heating}

In the same way as the compressive damage case, the results of tensile damage concrete are presented in Figure 9.

From the results presented, the steel concrete adhesion decreases with increasing temperature. This is mainly justified by the decrease in the mechanical properties of concrete. Also, the damages results ( $\mathrm{dc}$ and $\mathrm{dt}$ ) were in agreement with the results of Goto [31] pulling test concerning the direction of cracks in concrete as well as the distinction between cracks resulting from compressive stress and those resulting from tensile stress, Figure. 10. The Concrete damage at the interface steel-concrete is mainly due to compressive stress.
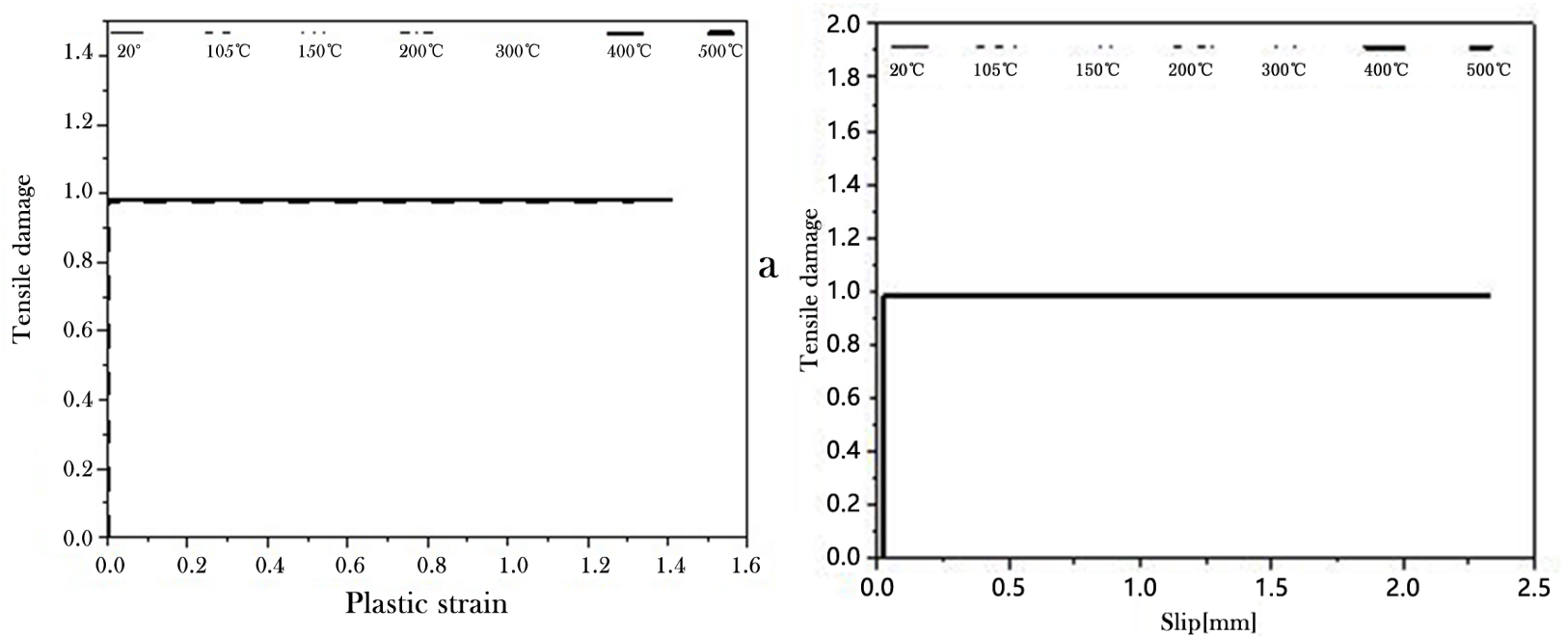

Figure 9. Evolution at different temperatures of tensile damage of concrete. (a) tensile damage-strain curve, (b) tensile damage slip curve

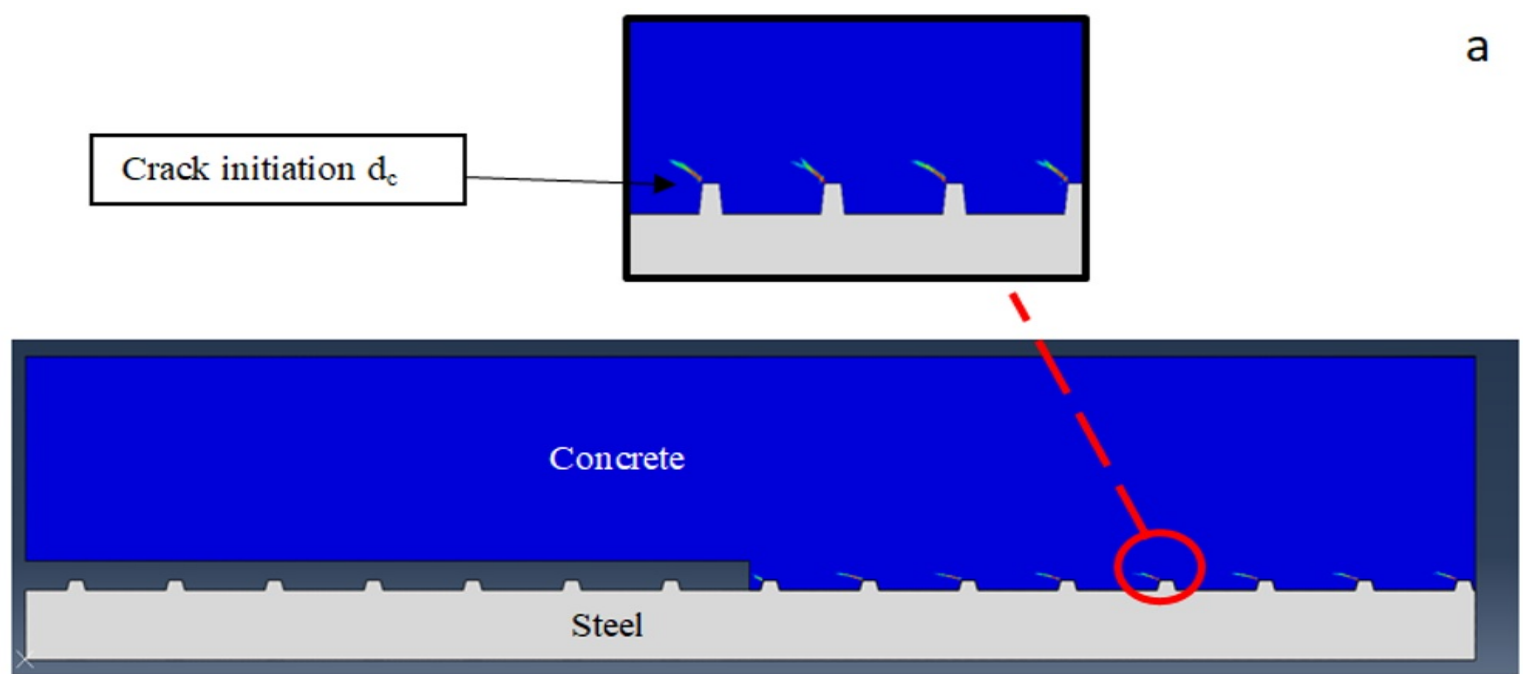




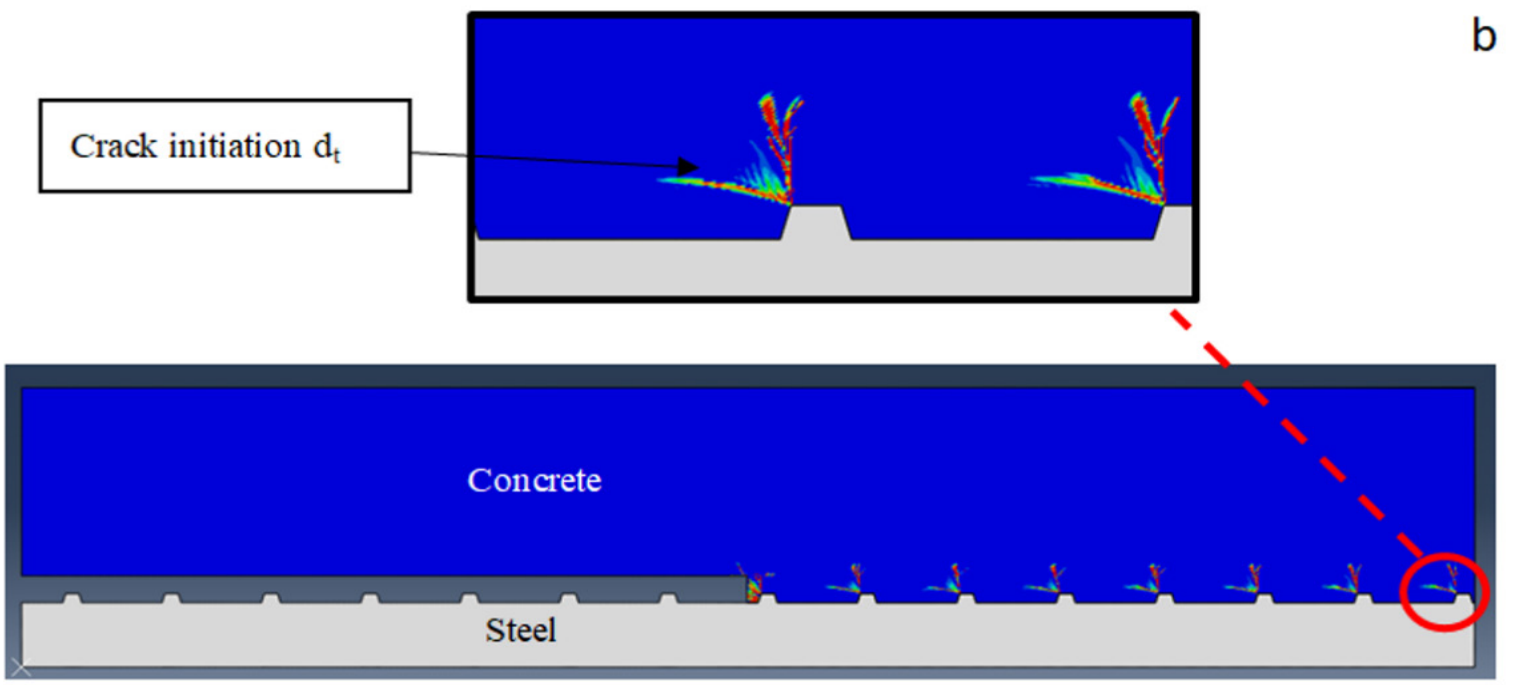

Figure 10. Damage initiation: (a) compression damage initiation, (b) tensile damage initiation

\section{Conclusions}

The following conclusions can be drawn from this numerical study:

Most considerable reduction of bond strength took place between $400^{\circ} \mathrm{C}$ and $500^{\circ} \mathrm{C}$. This observation with the various results mentioned show that using CDP model enables a proper definition of the failure mechanisms in concrete elements and that the bond between steel and concrete is the critical feature of reinforced concrete structures. It enables the use of concrete, which has a low tensile strength as a structural material.

The orientation of the propagation of damage is not affected by residual temperature effect.

The CDP can be used to model the behavior of concrete and the reinforced concrete structures during the warm-up phase. This numerical model does not simulate the different micro-structural changes that accompany concrete during its different heating and cooling phases.

\section{REFERENCES}

[1] M. R. Ben Romdhane. Caracterisation et modelisation numeriques de l'interface acier-beton, $\mathrm{PhD}$ thesis, ecole nationale des ponts et chaussees, Paris, 2004.

[2] M. Antonietta Aiello, M. Leone, M. Pecce. Bond performances of FRP rebars-reinforced concrete, Journal of materials in civil engineering, Vol. 19, No. 3, 205-213, 2007.

[3] X. Lin, X. Y. Zhang. Evaluation of bond stress-slip models for FRP reinforcing bars in concrete, Composite Structures, Vol. 107, 131-141, 2014

[4] S. Chu, A. Kwan. A new method for pull-out test of reinforcing bars in plain and fibre reinforced concrete, Engineering Structures, Vol. 164, 82-91, 2018.
[5] A. Rolland, M. Quiertant, A. Khadour, S. Chataigner, K.P. Argoul. Experimental investigations on the bond behavior between concrete and FRP reinforcing bars, Construction and building Materials, Vol. 173, 136-148, 2018.

[6] L. Huang, Y. Chi, L Xu, F.A. Deng. Thermodynamics-based damage-plasticity model for bond stress-slip relationship of steel reinforcement embedded in fiber reinforced concrete, Engineering Structures, Vol. 180, 762-778, 2019.

[7] S. B. Ka, S. J. Han, D. H. Lee, S. H. Choi, Y. H. Oh, K. S. $\mathrm{Kim}$. Bond strength of reinforcing bars considering failure mechanism, Engineering Failure Analysis, Vol. 94, 327-338, 2018.

[8] E. Kuliczkowska. Risk of structural failure in concrete sewers due to internal corrosion, Engineering Failure Analysis, Vol. 66, 110-119, 2016.

[9] M. Baena, L. Torres, A. Turon, C. Barris. Experimental study of bond behavior between concrete and FRP bars using a pull-out test", Composites Part B: Engineering 2009, Vol. 40, No. 8, 784-797, 2009

[10]Z. Li Z, J. Xu, E. Bai. Static and dynamic mechanical properties of concrete after high temperature exposure, Materials Science and Engineering: A, Vol. 544, 27-32, 2012.

[11]Z. Zenasni, S. Atlati, M. Haterbouch, K. Hannawi, W. P. Agbodgan, K. Nasri, M. Zenasni. Numerical study of the effect of concrete cover and the friction of steel concrete interface, MATEC Web of Conferences, Vol. 286, (02008). EDP Sciences, 2019.

[12]K. Lundgran, K. Gylltoft. A model for the Bond between Concrete and Reinforcement, Magazine of Concrete Research, Vol. 52, No 1, pp. 53-63, 2000.

[13] G. A. Khoury. Effect of fire on concrete and concrete structures, Progress in Structural Engineering and Materials, Vol. 2, No. 4, 429-447, 2000.

[14] A. K. Bui, T. C. Nguyen. "The Temperature Field in Mass Concrete with Different Placing Temperatures", Civil Engineering and Architecture, Vol. 8, No. 2, 94-100, 2020. DOI: $10.13189 /$ cea.2020.080207 
[15]A. Ghosh, modeling the bond stress at steel-concrete interface for uncorroded and corroded reinforcing steel, $\mathrm{PhD}$ thesis, Ryerson University, Bangladesh, 2000.

[16] Y. F. Chang, Y. H. Chen, M.S. Sheu, G. C. Yao. Residual stress-strain relationship for concrete after exposure to high temperatures, Cement and Concrete Research, Vol. 36, No. 10, pp.1999-2005, 2006.

[17]E. S. S. Lam, S. Fang. Direct tensile behavior of normal-strength concrete at elevated temperatures, ACI Materials Journal, Vol. 111, No. 6, 641-650, 2014.

[18]N. HNguyen, Dégradation du béton armé sous actions sévères : Etude du comportement résiduel de l'adhérence à l'aide de la technique d'émission acoustique. $\mathrm{PhD}$ thesis. Rennes, INSA. 2014.

[19] T. Jankowiak, T. Lodygowski. Identifcation of parameters of concrete damage plasticity constitutive model, Foundations of civil and environmental engineering, Vol. 6, No. 1, pp. 53-69, 2005.

[20] Y. N. Rabotnov, Creep problems in structural members, North-Holland, Amsterdam, 1969.

[21]E. Schlangen, Experimental and numerical analysis of fracture processes in concrete, Ph.D Thesis, Delft University of Technology. Delft, 1993.

[22] J. Davies. Observation of fracture path development in mortar beam specimens, Advanced Cement Based Materials Vol. 3, No.1, pp. 31-36, 1996.
[23]D. C. Drucker, W. Prager, Soil mechanics and plastic analysis or limit design, Quarterly of applied mathematics, Vol. 10, No. 2, pp.157-165. 1952.

[24] H. Kupfer, H. K. Hilsdorf, H. Rusch. Behavior of concrete under biaxial stresses, Journal Proceedings, Vol. 66, No. 8, pp.656-666, 1969.

[25]R. Tepfers, P. Olsson. Ring test for evaluation of bond properties of reinforcing bars. International Conference Bond in Concrete from Research to Practice, CEB Comité International du Béton, RTU Riga Technical University, Riga, Latvia 1, 1-89, (1992).

[26] J. J. Lubliner, S. O. Oliver, E. Oñate. A plastic-damage model for concrete, International Journal of Solids and Structures, Vol. 25, No. 3, 229-326, 1989.

[27] A. Ghosh, Lee J., G. L. Fenves. Plastic-damage model for cyclic loading of concrete structures, Journal of Engineering Mechanics, Vol. 124, No. 8, pp. 892-900, 1998.

[28] SIMULIA, Abaqus Theory Manual (6.14), Section 23.6.3, Providence, RI, USA, 2014.

[29] European committee for standardization, Eurocode 4: Design of composite steel and concrete structures-part 1-2: General rules-structure fire design, pp. 31-42, 2005.

[30] European committee for standardization, "Eurocode 2: Design of concrete structures-Part 1-2: General rules-structural fire design", pp. 19-26, 2004.

[31] Y. Goto. Cracks Formed in Concrete Around Deformed Tension Bars, ACI Journal, Vol. 68, No. 4, 244-251, 1971. 